\title{
Feasibility and Acceptability of a Mobile Technology Intervention to Support Postabortion Care in British Columbia: Phase I
}

Roopan Gill, MD, MPH, FRCSC; Gina Ogilvie, MD, MPH, PhD; Wendy V Norman, MD, MHSc, CCFP, FCFP; Brian Fitzsimmons, MD, FACOG, FRCSC; Ciana Maher, BA, MSc; Regina Renner, MD, MPH

Department of Obstetrics and Gynaecology, Women's Health Research Institute, University of British Columbia, Vancouver, BC, Canada

\section{Corresponding Author:}

Roopan Gill, MD, MPH, FRCSC

Department of Obstetrics and Gynaecology

Women's Health Research Institute

University of British Columbia

4500 Oak Street

Vancouver, BC,

Canada

Phone: 16043690774

Email: roopan.gill@gmail.com

\section{Abstract}

Background: Over 30\% of women in Canada undergo an abortion. Despite the prevalence of the procedure, stigma surrounding abortion in Canada leads to barriers for women to access this service. The vast majority of care is concentrated in urban settings. There is evidence to support utilization of innovative mobile and other technology solutions to empower women to safely and effectively self-manage aspects of the abortion process. This study is part 1 of a 3-phase study that utilizes user-centered design methodology to develop a digital health solution to specifically support follow-up after an induced surgical abortion.

Objective: This study aimed to (1) understand how women at 3 surgical abortion clinics in an urban center of British Columbia utilize their mobile phones to access health care information and (2) understand women's preferences of content and design of an intervention that will support follow-up care after an induced abortion, including contraceptive use.

Methods: The study design was based on development-evaluation-implementation process from Medical Research Council Framework for Complex Medical Interventions. This was a mixed-methods formative study. Women (aged 14-45 years) were recruited from 3 urban abortion facilities in British Columbia who underwent an induced abortion. Adaptation of validated surveys and using the technology acceptance model and theory of reasoned action, a cross-sectional survey was designed. Interview topics included demographic information; type of wireless device used; cell phone usage; acceptable information to include in a mobile intervention to support women's abortion care; willingness to use a mobile phone to obtain reproductive health information; optimal strategies to use a mobile intervention to support women; understand preferences for health information resources; and design qualities in a mobile intervention important for ease of use, privacy, and security. Responses to questions in the survey were summarized using descriptive statistics. Qualitative analysis was conducted with NVivo using a thematic analysis approach. This study was approved by the local ethics board.

Results: A waiting-room survey was completed by 50 participants, and semistructured interviews were completed with 8 participants. The average age of participants was 26 years. Furthermore, 94\% (47/50) owned a smartphone, 85\% (41/48) used their personal phones to go online, and $85 \%$ would use their cell phone to assist in clinical care. Qualitative analysis demonstrated that women prefer a comprehensive website that included secure email or text notifications to provide tools and resources for emotional well-being, contraceptive decision making, general sexual health, and postprocedure care.

Conclusions: A community-based mixed-methods approach allowed us to understand how women use their cell phones and what women desire in a mobile intervention to support their postabortion care. The findings from this formative phase will assist in the development and testing of a mobile intervention to support follow-up care after an induced surgical abortion.

(J Med Internet Res 2019;21(5):e13387) doi: 10.2196/13387

\section{KEYWORDS}

mHealth; family planning; abortion, induced; sexual health; digital health; user-centered design 


\section{Introduction}

\section{Background}

Despite abortion being without any criminal restriction in Canada and over $30 \%$ of women in Canada undergo an abortion, recent studies suggest that women who have an abortion experience isolation, particularly for those who travel far distances, perceived need for secrecy, feelings of stigma, and other social factors, suggesting that access to the procedure is only one aspect of what it means to deliver quality abortion care $[1,2]$. Specifically, studies have demonstrated that the dynamics of the political and social climate in Canada can lead to both externalized and internalized stigma for individuals who undergo an abortion $[1,3,4]$. Despite global guidance that states that follow-up is not necessary after an induced surgical abortion, there is evidence documenting women's desire for postabortion support [5-7]. Opportunities to use innovations using digital solutions for abortion care can support women to self-manage part, if not all, of the abortion process [6,8-11]. More importantly, evidence has pointed to its potential to provide follow-up support, particularly for women who live in rural and remote areas [4].

The intersection of digital health with self-care is moving rapidly and being utilized in various aspects of health care [12-17]. The New England Journal of Medicine published a special report on Telehealth—an example of digital health—in the United States, highlighting its utility and future. In 2016, Kaiser Permanente of Northern California reported that its virtual (email, telephone, and video) communications had exceeded in-person visits [18]. Similarly, research supports the safe and effective use of digital health solutions for provision of medical abortion care globally [19-25]. Evidence supports its safe, effective, and acceptable utility in provision of abortion. Studies utilizing hotlines, text messaging, and mobile apps in Cambodia, Indonesia, and South Africa are just a few examples of how digital health is being utilized to improve the abortion experience for women who face barriers to abortion care globally $[14,20,26,27]$. Despite the development and implementation of mobile health (mHealth) innovations for family planning, research is limited in understanding the follow-up needs of women who undergo an abortion, how they would perceive a digital health tool to support them, and more importantly, engage them as active participants in the design process.

\section{Objectives}

Given the existing evidence in support of mHealth for family planning innovations, we aimed to determine if a mobile technology intervention would be acceptable and feasible to women to support follow-up care after first and second trimester surgical abortion. This study was designed and conducted before the availability of mifepristone for medical abortion in Canada, and thus, women undergoing a surgical abortion were the focus population for this study [28]. We developed a 3-phased study based on user-centered design and the developmentevaluation-implementation process from Medical Research Council Frameworks for Complex Interventions [29]. Phase I was a mixed-methods formative design to understand how women at 3 surgical abortion clinics utilize their mobile phones to access health care information and to understand their preferences of content and design of a mobile intervention that will support follow-up care after a surgical abortion. Phase II was the design, development, and usability testing aspect of the study, and finally, phase III was a prospective mixed-methods pilot study to determine the feasibility and acceptability of the mobile intervention to support follow-up care after a surgical abortion. This study is the first to utilize mHealth and user-centered design in Canada as a novel approach to support follow-up care for women who undergo surgical abortion. The focus of this manuscript is phase I methodology and results.

\section{Methods}

\section{Participants}

Participants were recruited from publicly funded abortion clinics, 3 in urban settings and 1 in a rural site within British Columbia, Canada. The eligibility criteria were that the participant should (1) have consented to undergo a first or second trimester surgical abortion procedure, (2) be able to read and write English, (3) be able to participate in study procedures, and (4) be aged $\geq 14$ years. The participants were excluded if they were (1) attending the clinics because of fetal anomaly or miscarriage, (2) undergoing medical abortion, (3) in a situation that may be dangerous to utilize a mobile intervention, and (4) unable to provide consent to participate. To elicit whether a woman was in a dangerous situation, counselors asked patients as part of routine care if they felt safe in their current relationships. In cases where risk is identified, counselors provided resources and would refer to the appropriate provider or service.

\section{Theoretical Framework}

The study design and instruments were developed using the technology acceptance model (TAM) and theory of reasoned action (TRA). These theories have been validated in studies for the development of mHealth solutions in low- and middle-income countries [27,30,31]. TAM identifies 2 distinct attitudes that could predict the adoption of a new information system: perceived ease of use and usefulness of the system. TRA states that a person's behavior can be determined by 3 factors: (1) subjective norms, defined as whether or not people important to the individual believe they should perform the behavior or not; (2) individual's attitude toward the behavior; and (3) an individual's intention to engage in a behavior [30-32]. The study instruments for all 3 phases were developed using these theories based on validated survey tools [13,31,33,34]. Specifically, these tools have been utilized for formative research on developing digital health solutions specific to health behaviors.

\section{Study Design}

The overall study design is a mixed-methods user-centered design approach with 3 phases based on the development-evaluation-implementation process from the Medical Research Council Frameworks for Complex Medical Interventions [35]. Phase I is a community-based mixed-methods study conducted in 3 urban clinics in Vancouver, British Columbia, between May and August 2017 with the goal of 
understanding how women utilize technology to access health care information and their preferences of content and design of a mobile intervention to support follow-up care after an induced surgical abortion. The quantitative component of the study included an anonymous survey that was adapted from validated surveys from studies conducted for mHealth interventions and contraception use $[13,31,33,36]$. The survey asked questions about (1) how they use technology and their preferences for its use in clinical care and follow-up after an abortion, (2) mobile device use, privacy, and security, and (3) their past experience with contraception. The qualitative interview guide included topics on the types of wireless device used, technology engagement, acceptable information to include in a mobile intervention to support women's abortion care, willingness to use a mobile phone to obtain reproductive health information, optimal strategies to use the mobile intervention to support women, understanding preferences for health information resources, design qualities of mobile intervention, and privacy and security. Counselors at each of the abortion clinics obtained consent from eligible participants and distributed the survey for participants to complete in the waiting room or counselors' office before going for their procedure. Embedded within the survey, we asked participants whether they consented to being contacted within a week of their visit by our research coordinator to participate in an optional semistructured individual interview for the qualitative component of this study. Participants who consented to a follow-up telephone call received information regarding the qualitative component of the study, and if they were interested in participating, a convenient time was set for the principal investigator or the research coordinator to interview participants over the phone. Verbal consent was obtained at the start of the audio-recorded interviews, which lasted approximately $45 \mathrm{~min}$ each. Participants received a Can \$25 gift card for participating in the semistructured interview. A convenience sample of approximately 50 participants for the quantitative component of the study was desired and, for the qualitative component, 10 to 20 participants or until saturation of themes was reached. Studies have suggested that thematic saturation could be reached with as few as 12 to 15 participants [37].

This study was approved by the Children's and Women's Research Ethics Board (H16-02823).

\section{Data Analysis}

\section{Phase I}

Descriptive analysis of each variable from the waiting room survey was reported as a mean (SD) or median for continuous variables and count (\%) for categorical variables. The semistructured interview transcripts were uploaded to NVivo 11 (QSR International Pty Ltd) and read by 2 researchers. Inductive analysis was done to identify emerging themes, which were further refined through collaborative analysis with the first author and coinvestigator. Highlighted text was coded into nodes representing similar or repeating ideas. Some text was coded to more than 1 node to reflect the number of ideas presented. Nodes were then grouped together in a respective theme and a thematic map was developed and discussed with the research team and triangulation of data with expert opinion was used to enhance the validity of the findings.

\section{Results}

\section{Participant Characteristics}

Table 1 provides the demographic profile of participants. A total of 50 participants were recruited, and of these participants, $78 \%$ were Canadian, $84 \%$ were under the age of 30 years, $69 \%$ had an annual income less than Can $\$ 35,000$, and $36 \%$ had high school education, whereas $38 \%$ were between high school and a bachelor's degree. There was variation in the distance traveled by participants, with $30 \%$ traveling less than $10 \mathrm{~km}, 22 \%$ traveling between 20 and $40 \mathrm{~km}$, and $18 \%$ who traveled over $100 \mathrm{~km}$. In addition, 94\% (47/50) of participants reported owning a smartphone. Of the 50 participants who completed the survey, 25 consented to being contacted about the interview, and a total of 8 participants were recruited to participate in the semistructured individual phone interviews. 
Table 1. Demographic profile of participants $(\mathrm{N}=50)$.

\begin{tabular}{|c|c|}
\hline Demographic details & $\mathrm{n}(\%)$ \\
\hline \multicolumn{2}{|l|}{ Birthplace } \\
\hline Canada & $39(78)$ \\
\hline Other & $11(22)$ \\
\hline \multicolumn{2}{|l|}{ Age (years) } \\
\hline $18-25$ & $27(54)$ \\
\hline $26-30$ & $17(34)$ \\
\hline $31-37$ & $6(12)$ \\
\hline \multicolumn{2}{|l|}{ Annual income } \\
\hline Can $\$ 0-15,000$ & $16(31)$ \\
\hline Can $\$ 15,000-35,000$ & $18(38)$ \\
\hline Can $\$ 35,000-55,000$ & $8(17)$ \\
\hline Can $\$ 55,000+$ & $7(13)$ \\
\hline \multicolumn{2}{|l|}{ Education } \\
\hline High school & $17(36)$ \\
\hline Between high school and bachelor's & $19(38)$ \\
\hline Bachelor's or higher & $13(23)$ \\
\hline \multicolumn{2}{|l|}{ Distanced traveled to clinic } \\
\hline$<10 \mathrm{~km}$ & $15(30)$ \\
\hline $10-20 \mathrm{~km}$ & $5(10)$ \\
\hline $20-40 \mathrm{~km}$ & $11(22)$ \\
\hline $40-60 \mathrm{~km}$ & $6(12)$ \\
\hline $60-80 \mathrm{~km}$ & $4(8)$ \\
\hline $100+\mathrm{km}$ & $9(18)$ \\
\hline \multicolumn{2}{|l|}{ Own cell phone } \\
\hline Yes (basic) & $3(6)$ \\
\hline Yes (smartphone) & $47(94)$ \\
\hline
\end{tabular}

\section{Quantitative Results}

Results from the waiting room survey are summarized in Table 2. Specifically, $89 \%(42 / 47)$ of participants stated they use a smart phone most often out of a list of five commonly used devices, 92\% (45/49) of participants' phone plans included unlimited SMS plans, 92\% (45/49) of participants use the internet on their phone. 88\% (42/49) of the participants use their personal phones to go online, $85 \%$ (41/48) liked the idea of using a cell phone to assist in their clinical care and follow-up and $92 \%$ (45/49) of participants used mobile apps. Participants reported being more comfortable with receiving information about contraception, general postabortion care information, signs and symptoms after an abortion, mental health information and sexual health via email followed by website and mobile apps opposed to other modalities. Results are presented in Figures 1-4. 
Table 2. Phase I survey results.

\begin{tabular}{ll}
\hline Survey questions $(\mathrm{N}=50)$ & $\mathrm{n}(\%)$
\end{tabular}

Which device do you use?

Basic mobile phone

$4(8)$

Smartphone

47 (94)

Tablet

Laptop

Desktop computer

Which device do you use the most? $(\mathrm{N}=47)$

Basic mobile phone

Smartphone

$42(89)$

Tablet

Laptop

Desktop computer

All of the above

$1(2)$

When you have question about your health, what do you use? ( $N=50)$

Internet

Social media

$3(6)$

Mobile apps

Friends

$20(40)$

Family

Healthcare Provider

What do you use the most often? $(\mathrm{N}=50)$

Internet

Social media

Mobile app

$2(4)$

Friends

Family

$2(4)$

HP

Does your cell phone plan include text messaging? $(\mathrm{N}=49)$

Yes, pay per text

Yes, limited short message service (SMS)

Yes, unlimited SMS

$45(91)$

No

1 (2)

Don't know

Do you use the internet on your phone? $(\mathrm{N}=49)$

Yes

No

Don't know

Would like the idea of using cell phone to assist with follow-up care? ( $\mathrm{N}=48$ )

Yes

No

I don't know

How participants go online ${ }^{\mathrm{a}}(\mathrm{N}=49)$ 


\begin{tabular}{|c|c|}
\hline Survey questions (N=50) & $\mathrm{n}(\%)$ \\
\hline Personal computer & $34(69)$ \\
\hline Work & $7(14)$ \\
\hline Family/friends' computer & $5(10)$ \\
\hline Personal phone & $42(85)$ \\
\hline Internet café & $1(2)$ \\
\hline Family/friends' phone & $1(2)$ \\
\hline All of the above & $0(0)$ \\
\hline I don't go online & $0(0)$ \\
\hline \multicolumn{2}{|l|}{ Mobile app use (N=49) } \\
\hline Yes & $45(92)$ \\
\hline No & $3(6)$ \\
\hline I don't know & $1(2)$ \\
\hline \multicolumn{2}{|c|}{ Features that make a mobile app easy to use ${ }^{a}(N=49)$} \\
\hline Simple design & $44(90)$ \\
\hline Not overly time consuming & $31(63)$ \\
\hline Controlled push notifications & $18(37)$ \\
\hline Easy scrolling & $28(57)$ \\
\hline Link to other websites & $4(8)$ \\
\hline Log in by Facebook/Google+ & $16(33)$ \\
\hline Integration with other apps & $8 / 49(16)$ \\
\hline I don't know & $2(4)$ \\
\hline \multicolumn{2}{|c|}{ Frequency of messages from clinic $(\mathrm{N}=48)$} \\
\hline Daily & $1(2)$ \\
\hline Once/week & $14(29)$ \\
\hline Twice/week & $8(4)$ \\
\hline Once/month & $25(52)$ \\
\hline \multicolumn{2}{|c|}{ Prefer not to see the words abortion, birth control, and contraception in a text message ( $N=48)$} \\
\hline Yes, prefer if not used & $35(73)$ \\
\hline No, I don't care if they are used & $13(27)$ \\
\hline
\end{tabular}

${ }^{\mathrm{a}}$ Participants to mark all that applied. 
Figure 1. Number of participants who are comfortable receiving information about contraception via different modalities on their mobile device.

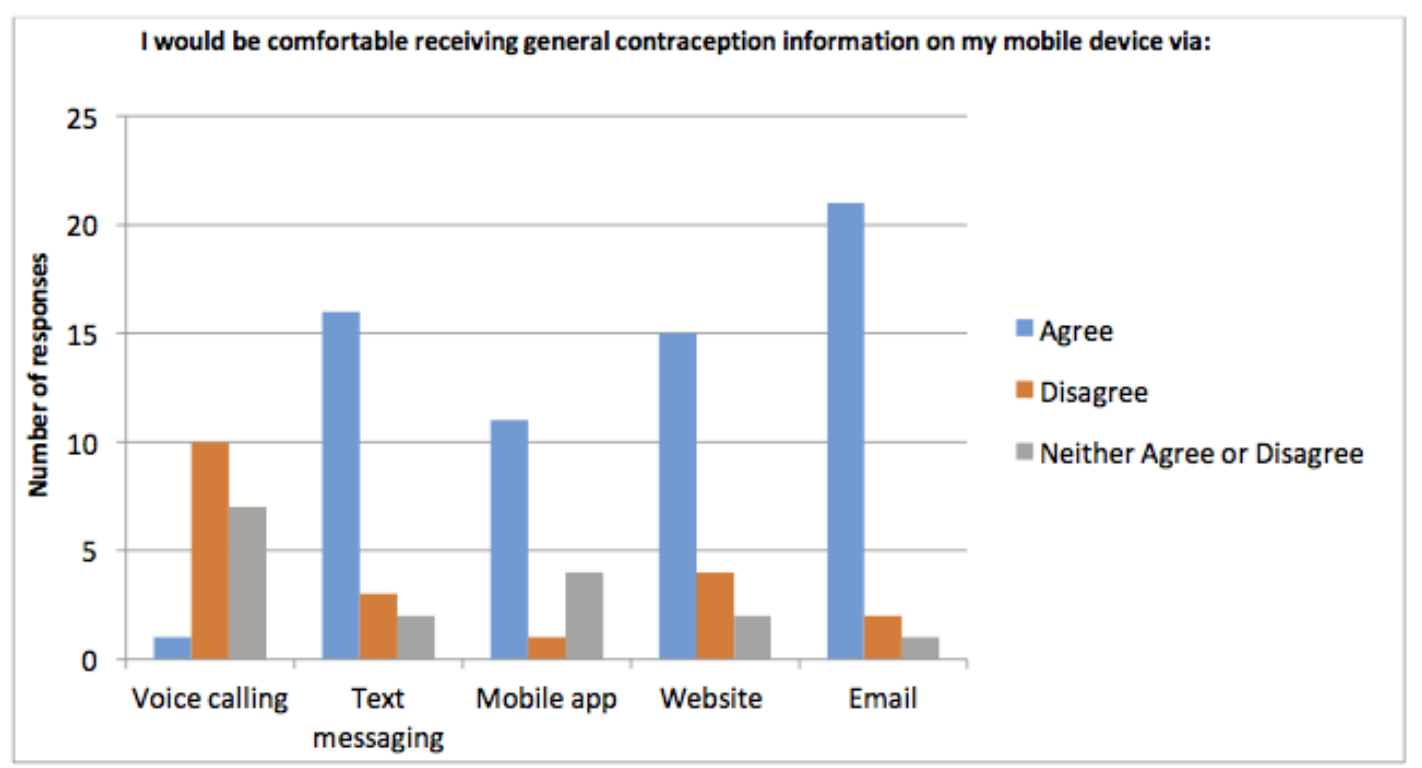

Figure 2. Number of participants who are comfortable receiving information about postabortion care via different modalities on their mobile device.

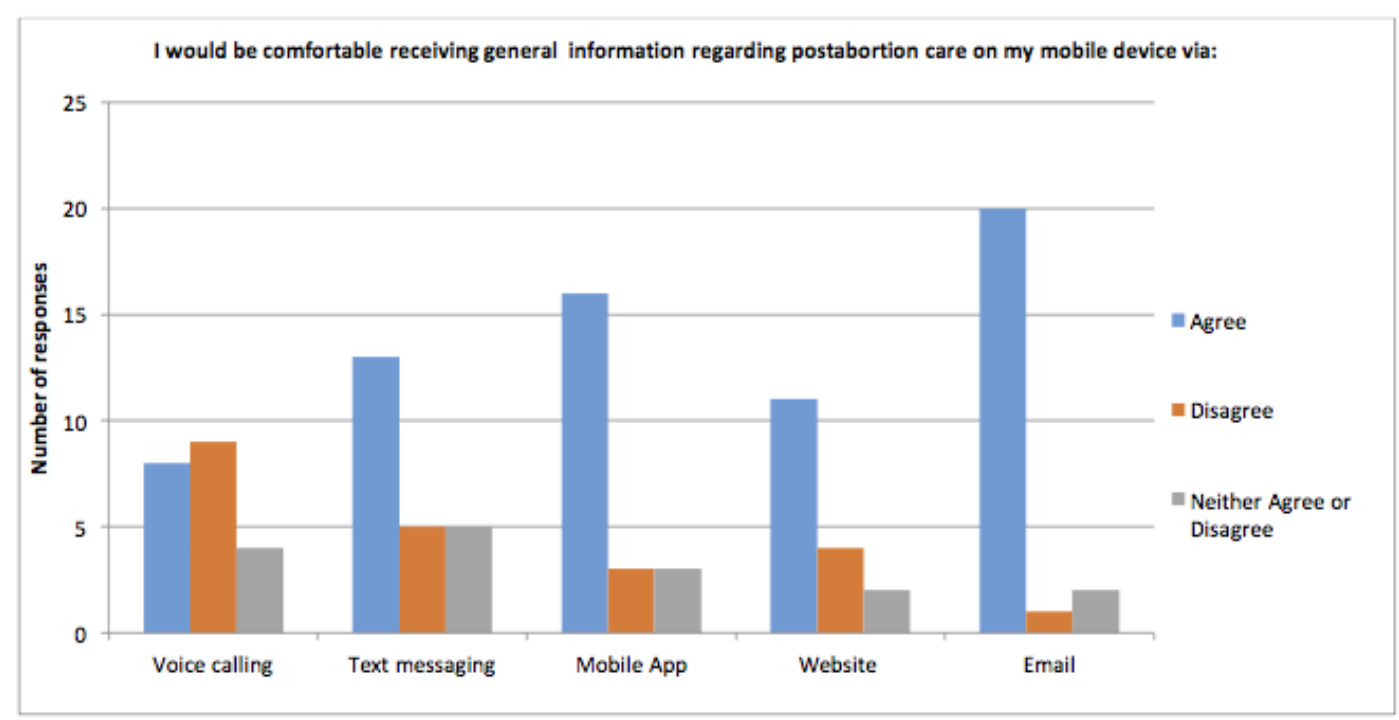

Figure 3. Number of participants who are comfortable receiving information about postoperative signs and symptoms via different modalities on their mobile device.

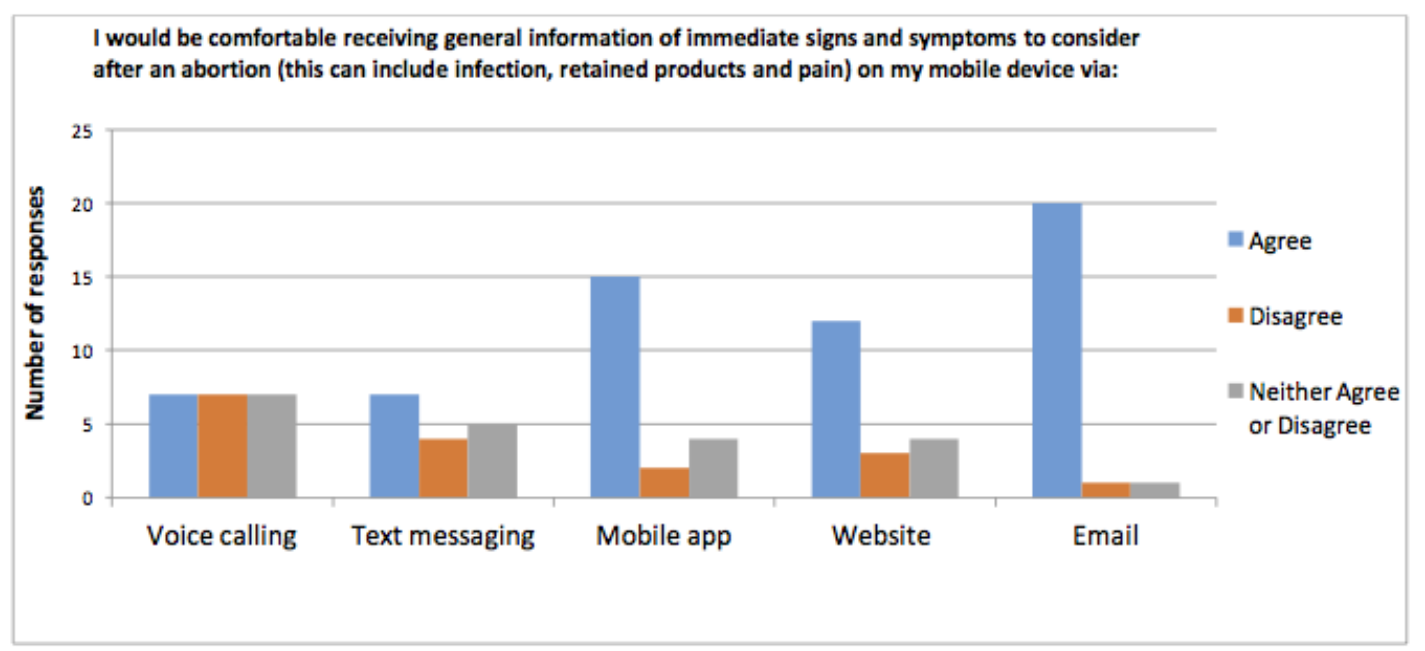


Figure 4. Number of participants who are comfortable receiving information about mental health via different modalities on their mobile device.

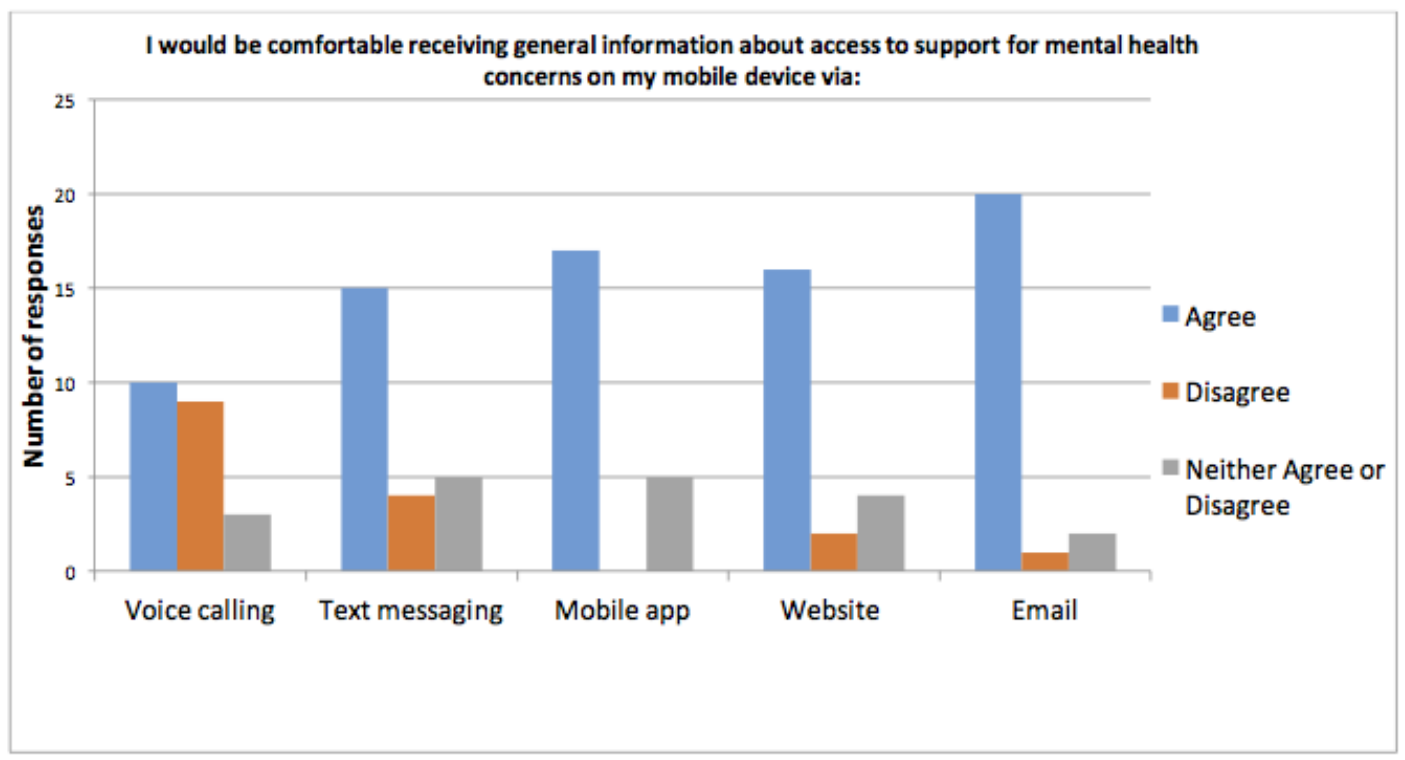

Figure 5 highlights previous contraceptive use. The top 2 Semistructured Interviews methods were oral contraceptives, followed by condoms. Participants were asked if they were using a birth control method just before the index pregnancy and $48 \%(24 / 50)$ stated yes, $28 \%(14 / 50)$ said no, and 24\% (12/50) said sometimes.

We further explored questions around contraceptive use and behavior using an adapted version of ORTHO Birth Control Satisfaction Assessment Tool [33]. We analyzed the questions according to lifestyle impact (63), compliance/adherence (51), and assurance/confidence on a scale of 0 to 100 (58). Higher scores indicate better satisfaction; however, the results ranged between 50 and 65 , suggesting that participants were neutral with regard to the degree of satisfaction with previous contraceptive use. This information was used to assist with content and design elements for the mobile intervention.

A thematic analysis approach was used to analyze the interviews. We explored themes around 3 specific categories: (1) participants' overall abortion experience and how that may inform their thoughts on follow-up both for physical and/or emotional well-being, (2) current level of interaction with technology and specifically around health care-based issues, and (3) preferences for a mobile intervention to support follow-up care following a surgical abortion. Overall, 10 key themes were identified. These are listed in Textbox 1 with definitions of each on the basis of the various nodes and subnodes that were established from the analysis. Half of the participants who were interviewed traveled greater than $50 \mathrm{~km}$ to obtain care at 1 of the 3 urban abortion clinics. Importantly, they noted that for women such as themselves who travel far distances or are from rural areas, a resource that is comprehensive, secure, simple, and accessible is an important need and would address a gap in postabortion care.

Figure 5. Previous contraceptive methods (numerical representation), $n=50$.

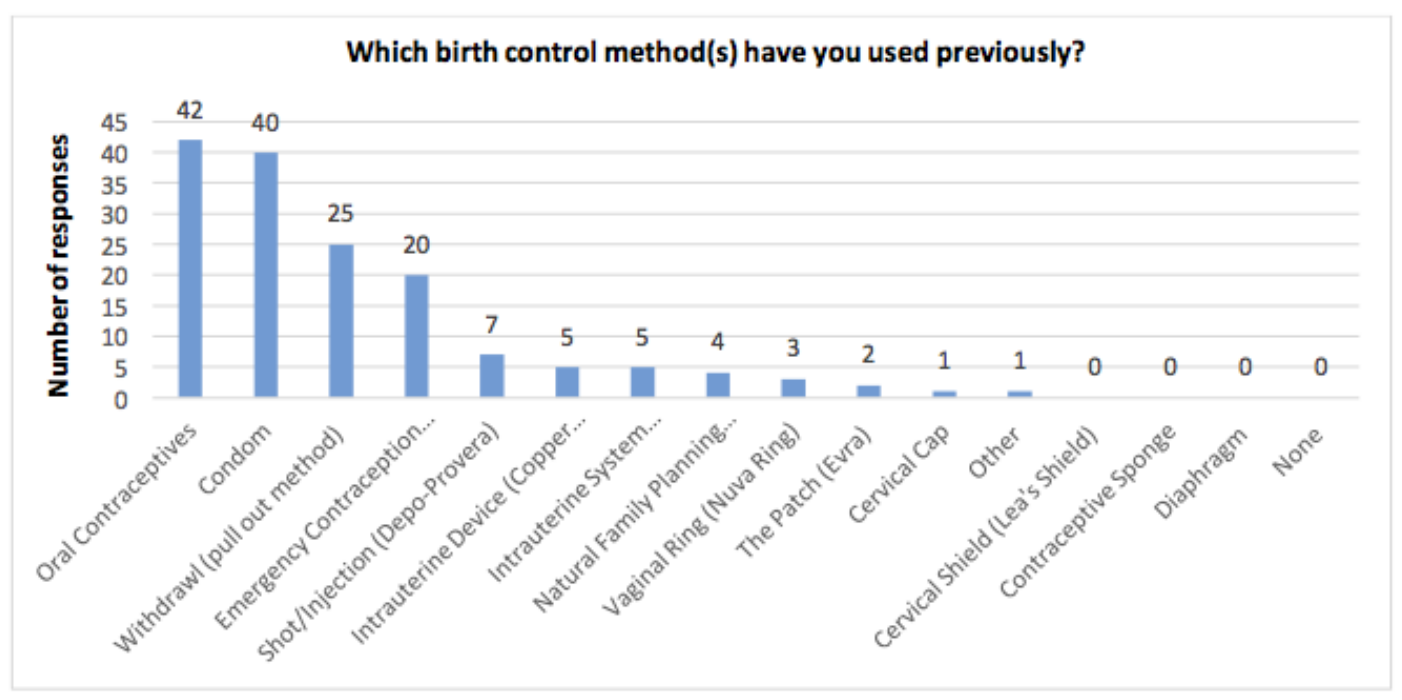


Textbox 1. Definitions of themes on basis of nodes and subnodes. (Numbers represent the nodes and the letters [a, b, c...] represent the subnodes.)

Talking about abortion

- $\quad$ Decision making

- Abortion experience at the clinic

- Stigma

Accessing health information

- Health professionals

- Internet

- Friends/family

- $\quad$ Other sources

Barriers to health care

- $\quad$ Time

- Appointments/wait times

Contraception

- Access

- Education

- $\quad$ Current and past use

- Motivation

- $\quad$ Side effects

Desire for Postabortion counseling

- Accessing counseling

General Postprocedure needs

- Physical

- Emotional

- Support networks

Understanding follow-up

- Definition

- $\quad$ Needed

- Desired

Features and considerations of a mobile intervention

- Design

- Content
i. Language
ii. Topics

- $\quad$ Experience with previous mobile apps

Features and considerations for a text messaging service

- Content

- Convenience

- $\quad$ Frequency

- $\quad$ Preference 


\section{Talking About Abortion}

Participants unanimously described the experience as lonely, particularly as they felt that they were unable to talk to someone about the procedure. When asked if participants would want an intervention that allowed them to connect with other women or to resources where women share their stories, many supported this. One participant stated:

\section{...I like the principle of women being able to talk about their experiences and I think that just creates more and more awareness, and awareness is a positive thing}

Some felt that for religious or cultural reasons they may not feel comfortable speaking to their health care provider and that having a mobile intervention that was comprehensive and evidence based would be a good way to access information.

\section{Accessing Health Information}

The majority of our participants utilized Google as their first point to access information but did not view this as a panacea to health information. Ultimately, participants preferred to obtain information from a trusted health care provider. One participant stated:

...sometimes I would probably go online first and just Google things and try and find things out but I usually try and go to a doctor eventually. When I go online it's just like premature before I decide to go to the doctor

Participants would also use the internet to elicit opinions of other women on birth control:

\section{Googled it [referring to the intrauterine device] to see what people thought of it. I do that with every kind of birth control. But at the same time you have to take it with a grain of salt because people don't post reviews on contraception if they like it. They only post negative reviews.}

This information was useful for our study team and key stakeholders when considering content development for contraception.

\section{Barriers to Health Care}

Participants provided valuable information to highlight that stigma around abortion continues to exist among health care providers and specifically in rural areas. This theme was valuable to consider when we engaged with our rural key stakeholders to share and elicit information from their perspective of the challenges of rural abortion care. One participant stated:

I live in a remote community. For sure, and it's a really small town. So I probably wouldn't even feel comfortable going to somebody because it's a small town.

Another participant commented that there is not enough information on the abortion services provided in British
Columbia on the internet, and rather, the first resources that are presented are pregnancy options services that are in fact centers to convince women to keep their pregnancies. This participant stated:

...because when I was looking it up on the Internet a bunch of places came up for pregnancy options but none for actual clinics that do these procedures and what not.

This highlighted that we needed to consider a resource that had a comprehensive and vetted list of resources that women could refer to.

\section{Contraception}

We asked participants about their contraceptive behaviors and preferences because this is a component of abortion care and subsequent follow-up. Participants shared their frustration that contraception is not free in Canada. Furthermore, concerns about good access were brought up frequently, as was the need to be well informed that contraception is not just for pregnancy prevention but also for prevention of sexually transmitted infections. Participants were motivated to use contraception to prevent future pregnancies.

\section{Desire for Postabortion Counseling}

This was a consistent theme among participants. Many stated that it would be useful to have access in person as well as remotely to postabortion counseling. One participant who had her second procedure had used counseling postabortion after her first termination and stated:

when I first got a termination years ago, I was super against it [counselling] because I was an idiot and I was 20. And then I did it anyway and it was the best thing I could have ever done.

\section{General Postprocedure Needs}

We asked participants about their general postprocedure needs. The vast majority felt good physically but found more emotional hardships. One participant stated:
Physically I felt better than I expected. I was in bed for maybe a day, but it wasn't bad. It wasn't painful. Like, I have bad cramps on my period and it was at most like that. But that only lasted a short time. But otherwise the pregnancy symptoms left pretty quickly, I guess in about a week, some of them sooner than that.

On the emotional experience, a participant stated:
Emotionally it was harder than I expected it to be. I knew that this was something I needed to do if this was to happen. But I never obviously had to do it before, so it was definitely harder, even though I knew it was the right thing to do. It still brought up a lot of emotional questions and feelings.

Another participant highlighted the importance for a postprocedure intervention to include a phone call or text 
message that would be a check-in with the patient. Many stated it was an isolating and lonely experience and to have either a service that connected them to other resources and services or a live chat group would be something valuable.

\section{Understanding Follow-Up}

Despite follow-up being an important aspect of health care, there are little data published that examine how individuals perceive follow-up. This is important to consider when developing a postabortion support tool. When asked what follow-up means, a participant stated:

...with a healthcare provider, I guess just following up with any physical, medical relevant issues.

Furthermore, some participants expressed desiring follow-up based on whether or not they had an intrauterine device inserted at the time of abortion. One participant stated:

They just told me to come back in six weeks to get an ultrasound of my IUD to make sure it's in the right place...and I'm assuming they'll probably see how I'm feeling emotionally, physically and - that was my understanding of the follow-up.

When we asked participants whether they felt follow-up was needed and/or desired, a vast majority stated that it would be desired for emotional support, and they did state it was a necessity physically as that was what was told to them at the time of their procedure. However, many had recovered physically a few days after and noted that emotional and social support was desired. Some also commented that it might be good to have a mobile intervention that allowed women who lived in remote communities to have access to. The following are excerpts from individuals who highlighted the desire for emotional support and the benefit of a secure resource for those living in rural areas.

\section{I feel like it's a-like, for mental health I feel like maybe it's more desired \\ I think it would probably be beneficial for more people who are living in more rural or conservative communities who might not feel comfortable talking to their doctor or don't have very good access to the aftercare. I'm fine 'cause I'm in downtown Vancouver. But other people might not have such an easy time.}

\section{Features and Considerations of a Mobile Intervention}

Participants consistently stated that they wanted an easy-to-navigate, simple, professional mobile intervention that was concise and user-friendly. In addition, 2 of our participants expressed that it should be:

Easy to navigate...more simple, straightforward but with options to look at more information if you wanted some

and:

I think just simplicity and user-friendly ease sort of is important. Not having too much information which to be honest I don't know how you do it because there's a lot of information on this topic.
Participants also stated that the intervention should allow them to unsubscribe, particularly, if it included text or email notifications. There was also encouragement to include partners in the intervention and to have information relevant for partners specifically. One participant commented on the importance to ensure that the app or website is functioning and checked frequently. She stated:

\section{Mediocre apps are just an inconvenience, and I feel like this category, it's not-I don't know, I feel like it just wouldn't get the funding that it needed for it to really work properly. I have no patience for apps that don't work well. So if it's not awesome, it's not on my phone and I'm not wasting my time using it.}

Participants suggested that options listed in the form of a dropdown list would allow for ease of navigation. Participants also wanted to be able to book counseling services directly online with the counselors from the respective abortion clinics where they received services. This was a service already provided by the counselors but participants encouraged this be part of a follow-up mobile technology resource. Finally, having more concise, patient-centered information on contraception in an easy-to-access manner was an expressed need:
More information on contraception and all the different types that women can use because I know a lot of my girlfriends the only type they use is a condom or birth control...I feel like there should be more information on the IUDs because it would be a really good alternative for some women who are like me and would prefer just to not have to worry about taking oral contraceptives at a certain time if they're busy or something like that. Because my current experience with birth control is after going to the clinic and receiving the information that I got, I realized the IUD was best for me. And there should be more information about that, whether it be on an app or on the Internet.

\section{Features and Considerations for a Text Messaging Service}

Overall, participants encouraged follow-up by either an individual from the clinic texting them at set times or an email or text messaging service that was automatic and timed in appropriate frequencies. It was important that there be an unsubscribe feature. Furthermore, participants stated that weekly messages at first would be useful but then to decrease these messages to monthly up to a maximum of 6 months. The following excerpts highlight this theme:

I think it's a really good thing. I would definitely have somebody remind me about appointments, remind me to get a checkup,...I would definitely use that. But I think as well-as long as you consent to it and you can set the frequency yourself, like, I think it's a great idea.

I think that would be handy as long as it had the option to stop at any time, an unsubscribe feature 


\section{Privacy and Confidentiality}

Privacy and confidentiality was very important for women who were interviewed, which was slightly different from the results of the quantitative survey. Participants stated that they would want something that is discrete and did not mention the words abortion or have any way to link the patient to the clinic where they had their procedure:

I think confidentiality is a big part of it, just because-especially with some people, they don't really want everyone to know. I know I don't want everybody in the whole world to know what happened.

Privacy is everything for me. That's the most important thing for me. And I think that's maybe because I do live in a small town. It's really, really important to have that here. If you're in a big anonymous city it might be different.

Obviously with mobile technology you want to be really considerate of privacy and have secure servers and-especially if there's contact information with a whole list of women... as it relates to mobile, that's definitely something to consider.

\section{Discussion}

This study represents the first phase of a 3-phase study and highlights the importance of formative research that incorporates the voice of end users to assist with development of a mobile intervention for follow-up after an induced surgical abortion. Specifically, this formative mixed-methods study explored women's interactions with technology and important aspects to design and content for a mobile intervention to support follow-up after a surgical abortion. It is important to include a formative aspect to the development of technology-based interventions to improve women's health generally, but abortion care specifically [20,36,38-40]. The theoretical framework for all 3 phases included both the TAM and TRA theories. In this study particularly, we were able to elicit information about what would be important in the design of the tool, what are the contextual factors to consider in designing the tool but also around the stigma women continue to experience around abortion and how that can inform one's attitude and intentions to engage in a tool to support them in care related to an abortion. This information was utilized in the development of the intervention and further testing for phases II and III.

According to the literature, including the voice of end users early in the development of an intervention is a fundamental principle of human-centered design [16,20,38,39]. A study conducted by Smith et al [20] explored women's needs in Cambodia to develop a mobile phone-based intervention to support postabortion family planning, specifically, contraceptive adherence [20]. Similarly, researchers from University of San Francisco's Program in Women-Centered Contraception, developed a tablet-based contraceptive decision support tool for women [41]. This study utilized a multiphase approach that incorporated the end user throughout the entire design of the project. The formative research findings from these studies emphasized that using an iterative process informed by patient and provider input throughout the development and testing led to a more patient-centered innovation [42]. In addition, the formative research in these studies identified main patterns of mobile use of the women from the respective countries, main reasons and expectations for contraception and abortion care, researchers drew on components of existing interventions and behavior change theories to then develop conceptual frameworks. It also highlights that anytime a mobile intervention is to be adapted to a new context, formative research is essential to ensure the tool can be adapted to particular contexts and cultures.

In this study, a theme that resonated was the desire for a tool that incorporated emotional support as part of follow-up abortion care, which has been previously described in the published literature. A qualitative study conducted in Canada explored women's abortion experiences in the Yukon territory, a remote service area, highlighting that "fragmented services left women unsatisfied, stressed and upset about lack of information, multiple appointments and lengthy wait times" [43]. Women further expressed frustration with lack of follow-up counseling and recommended that it be routinely offered as they feel contact with health care providers is cut off after the procedure [43]. In addition to access issues, barriers of cost, knowledge among the general public, health care provider competence, and attitudes have also been highlighted in the literature [44]. Another study explored women's expressed desire for postabortion support services, highlighting the stigma around abortion that exists in political and social contexts, preventing women from sharing their experiences [1]. This study specifically highlighted that though women may not necessarily need mandatory physical follow-up, they desire access to postabortion support for emotional well-being [1]. Furthermore, there is great deal of inconsistency in the type of support and information available to women after an abortion. In addition to emotional support, participants stressed key characteristics of the mobile intervention such as privacy and confidentiality, evidence-based information, some form of interaction with the health care system, and is professional and easy to use.

Finally, it was important to capture the voice of women who traveled from rural and remote areas. According to our demographic data, over one-third of our participants traveled over $50 \mathrm{~km}$ to obtain an abortion. Though abortion is legal in Canada, there are access barriers, particularly for women living in remote and rural areas. Studies that have developed strategies in restrictive settings utilizing mHealth could be adapted to rural and remote contexts that have restricted access to abortion services in Canada. Providing safe and effective means, such as telemedicine, text messaging services, or mobile apps, has been proven to be acceptable and satisfactory for women in legally restricted settings [12,21-23,26] and, therefore, could have potential for Canadian women living in rural and remote areas, where abortion is legal but barriers to service delivery exist.

The limitations for this study include overall generalizability to other populations and small convenience sample sizes. Furthermore, abortion continues to be stigmatized, which can contribute to difficulties with recruitment and loss to follow-up. Accordingly, we noted that recruitment for the qualitative interviews took longer than expected and further assumed that 
lack of participant engagement may be associated with conducting research a few weeks out after the abortion, where participants have moved on and are resuming back in their busy lives. Consideration of recruitment strategies will need to be taken into consideration for future studies, particularly when thinking about diversifying the participants recruited and obtaining robust response rates for analysis.

Balancing these limitations are the strengths of our study, including user engagement early in the research design, a mixed-methods design incorporating both quantitative and qualitative data, engagement with both urban and rural key stakeholders, and robust findings that will inform the design of the mobile intervention.

Details of phases II and III will be published as separate papers. Specifically, phase II incorporated these findings to develop, design, and test an intervention based on findings from this study, and phase III was a pilot, prospective mixed-methods study to determine the feasibility and acceptability of the tool for women who undergo a surgical abortion.

\section{Implications}

This study was the first phase of 3 and perhaps the most important phase as it determined crucial findings about women's interactions with technology and their preferences for design and content of an intervention that could support their care after a surgical abortion. Moreover, there is great deal of momentum toward self-managed abortion care and technology has a role to play. This study is the first to utilize mHealth and user-centered design in Canada as a novel approach to provide a means for women to self-manage their follow-up care after a surgical abortion.

\section{Conflicts of Interest}

None declared.

\section{References}

1. LaRoche KJ, Foster AM. "I kind of feel like sometimes I am shoving it under the carpet”: documenting women's experiences with post-abortion support in Ontario. FACETS 2017 Sep;2(2):754-763. [doi: 10.1139/facets-2017-0059]

2. Norman WV. Induced abortion in Canada 1974-2005: trends over the first generation with legal access. Contraception 2012 Feb;85(2):185-191. [doi: 10.1016/j.contraception.2011.06.009] [Medline: 22036474]

3. LaRoche K, Foster AM. Toll free but not judgment free: evaluating postabortion support services in Ontario. Contraception 2015 Nov;92(5):469-474. [doi: 10.1016/j.contraception.2015.08.003] [Medline: 26260687]

4. Sethna C, Doull M. Spatial disparities and travel to freestanding abortion clinics in Canada. Womens Stud Int Forum 2013 May;38:52-62. [doi: 10.1016/j.wsif.2013.02.001]

5. World Health Organization. 2012. Safe abortion: technical and policy guidance for health systems, 2nd Edition URL: https:/ /www.who.int/reproductivehealth/publications/unsafe abortion/9789241548434/en/ [accessed 2019-05-12] [WebCite Cache ID 78Jysuww5]

6. World Health Organization. 2015. Health worker roles in providing safe abortion care and post-abortion contraception URL: https://www.who.int/reproductivehealth/publications/unsafe abortion/abortion-task-shifting/en/ [accessed 2019-05-12] [WebCite Cache ID 78Jz9bRsU]

7. National Abortion Federation. 2018. Clinical Policy Guidelines URL: https://prochoice.org/resources/ clinical-policy-guidelines/ [accessed 2019-05-16] [WebCite Cache ID 78PzsXe6u]

8. Wainwright M, Colvin CJ, Swartz A, Leon N. Self-management of medical abortion: a qualitative evidence synthesis. Reprod Health Matters 2016 May;24(47):155-167 [FREE Full text] [doi: 10.1016/j.rhm.2016.06.008] [Medline: 27578349]

9. Gerdts C, Tunçalp O, Johnston H, Ganatra B. Measuring abortion-related mortality: challenges and opportunities. Reprod Health 2015 Sep 16;12:87 [FREE Full text] [doi: 10.1186/s12978-015-0064-1] [Medline: 26377189]

10. Murtagh C, Wells E, Raymond EG, Coeytaux F, Winikoff B. Exploring the feasibility of obtaining mifepristone and misoprostol from the internet. Contraception 2018 Dec;97(4):287-291 [FREE Full text] [doi:

10.1016/j.contraception.2017.09.016] [Medline: 29030227]

11. Bracken H, Lohr PA, Taylor J, Morroni C, Winikoff B. RU OK? The acceptability and feasibility of remote technologies for follow-up after early medical abortion. Contraception 2014 Jul;90(1):29-35. [doi: 10.1016/j.contraception.2014.03.016] [Medline: 24815098]

12. Grossman D, Grindlay K. Safety of medical abortion provided through telemedicine compared with in person. Obstet Gynecol 2017 Dec;130(4):778-782. [doi: 10.1097/AOG.0000000000002212] [Medline: 28885427]

13. Lester R, Ritvo P, Mills EJ, Kariri A, Karanja S, Chung MH, et al. Effects of a mobile phone short message service on antiretroviral treatment adherence in Kenya (WelTel Kenya1): a randomised trial. Lancet 2010 Nov 27;376(9755):1838-1845. [doi: 10.1016/S0140-6736(10)61997-6] [Medline: 21071074]

14. de Tolly KM, Constant D. Integrating mobile phones into medical abortion provision: intervention development, use, and lessons learned from a randomized controlled trial. JMIR Mhealth Uhealth 2014 Feb 14;2(1):e5 [FREE Full text] [doi: 10.2196/mhealth.3165] [Medline: 25098569]

15. Labrique AB, Vasudevan L, Kochi E, Fabricant R, Mehl G. mHealth innovations as health system strengthening tools: 12 common applications and a visual framework. Glob Health Sci Pract 2013 Aug;1(2):160-171 [FREE Full text] [doi: 10.9745/GHSP-D-13-00031] [Medline: 25276529] 
16. Gilbert M, Haag D, Hottes TS, Bondyra M, Elliot E, Chabot C, et al. Get Checked... Where? The development of a comprehensive, integrated internet-based testing program for sexually transmitted and blood-borne infections in British Columbia, Canada. JMIR Res Protoc 2016 Sep 20;5(3):e186 [FREE Full text] [doi: 10.2196/resprot.6293] [Medline: 27649716]

17. World Health Organization. 2018. Classification of Digital Health Interventions v1.0 URL: https://www.who.int/ reproductivehealth/publications/mhealth/classification-digital-health-interventions/en/ [accessed 2019-05-12] [WebCite Cache ID 78K15eTRy]

18. Tuckson R, Edmunds M, Hodgkins ML. Telehealth. N Engl J Med 2017 Oct 19;377(16):1585-1592. [doi: 10.1056/NEJMsr1503323] [Medline: 29045204]

19. Wiebe ER. Use of telemedicine for providing medical abortion. Int J Gynaecol Obstet 2014 Feb;124(2):177-178. [doi: 10.1016/j.ijgo.2013.07.038] [Medline: 24332519]

20. Smith C, Vannak U, Sokhey L, Ngo TD, Gold J, Free C. Mobile Technology for Improved Family Planning (MOTIF): the development of a mobile phone-based (mHealth) intervention to support post-abortion family planning (PAFP) in Cambodia. Reprod Health 2016 Jan 5;13(1):1-015. [doi: 10.1186/s12978-015-0112-x]

21. Grindlay K, Lane K, Grossman D. Women's and providers' experiences with medical abortion provided through telemedicine: a qualitative study. Womens Health Issues 2013;23(2):e117-e122. [doi: 10.1016/j.whi.2012.12.002] [Medline: 23410620]

22. Aiken A, Digol I, Trussell J, Gomperts R. Self reported outcomes and adverse events after medical abortion through online telemedicine: population based study in the Republic of Ireland and Northern Ireland. Br Med J 2017 May 16;357:j2011 [FREE Full text] [doi: 10.1136/bmj.j2011] [Medline: 28512085]

23. Aiken A, Gomperts R, Trussell J. Experiences and characteristics of women seeking and completing at-home medical termination of pregnancy through online telemedicine in Ireland and Northern Ireland: a population-based analysis. BJOG 2017 Jul;124(8):1208-1215 [FREE Full text] [doi: 10.1111/1471-0528.14401] [Medline: 27748001]

24. Smith C, Ngo TD, Gold J, Edwards P, Vannak U, Sokhey L, et al. Effect of a mobile phone-based intervention on post-abortion contraception: a randomized controlled trial in Cambodia. Bull World Health Organ 2015 Dec 01;93(12):842-50A [FREE Full text] [doi: 10.2471/BLT.15.160267] [Medline: 26668436]

25. Free C, Phillips G, Galli L, Watson L, Felix L, Edwards P, et al. The effectiveness of mobile-health technology-based health behaviour change or disease management interventions for health care consumers: a systematic review. PLoS Med 2013;10(1):e1001362 [FREE Full text] [doi: 10.1371/journal.pmed.1001362] [Medline: 23349621]

26. Gerdts C, Hudaya I. Quality of care in a safe-abortion hotline in Indonesia: beyond harm reduction. Am J Public Health 2016 Dec;106(11):2071-2075. [doi: 10.2105/AJPH.2016.303446] [Medline: 27631756]

27. Mburu S, Franz E, Springer T. A conceptual framework for designing mHealth solutions for developing countries. In: Proceedings of the 3rd ACM MobiHoc workshop on Pervasive wireless healthcare. 2013 Presented at: ACM MobiHoc workshop on Pervasive wireless healthcare; July 29-29, 2013; Bangalore, India p. 1-6. [doi: 10.1145/2491148.2491154]

28. Dunn S, Cook R. Medical abortion in Canada: behind the times. Can Med Assoc J 2014 Jan 07;186(1):13-14 [FREE Full text] [doi: 10.1503/cmaj.131320] [Medline: 24277708]

29. Eckman M, Gorski I, Mehta K. Leveraging design thinking to build sustainable mobile health systems. J Med Eng Technol 2016;40(7-8):422-430. [doi: 10.1080/03091902.2016.1218560] [Medline: 27535325]

30. Holden RJ, Karsh BT. The technology acceptance model: its past and its future in health care. J Biomed Inform 2010 Feb;43(1):159-172 [FREE Full text] [doi: 10.1016/j.jbi.2009.07.002] [Medline: 19615467]

31. Smillie K, Van Borek N, Abaki J, Pick N, Maan EJ, Friesen K, et al. A qualitative study investigating the use of a mobile phone short message service designed to improve HIV adherence and retention in care in Canada (WelTel BC1). J Assoc Nurses AIDS Care 2014;25(6):614-625 [FREE Full text] [doi: 10.1016/j.jana.2014.01.008] [Medline: 24768442]

32. Davis F, Bagozzi R, Warshaw P. User acceptance of computer technology: a comparison of two theoretical models. Manag Sci 1989 Aug;35(8):982-1003. [doi: 10.1287/mnsc.35.8.982]

33. Colwell H, Mathias SD, Cimms TA, Rothman M, Friedman AJ, Patrick DL. The ORTHO BC-SAT--a satisfaction questionnaire for women using hormonal contraceptives. Qual Life Res 2006 Dec;15(10):1621-1631. [doi: 10.1007/s11136-006-0026-8] [Medline: 17031502]

34. Gilbert M, Salway T, Haag D, Fairley CK, Wong J, Grennan T, et al. Use of GetCheckedOnline, a comprehensive web-based testing service for sexually transmitted and blood-borne infections. J Med Internet Res 2017 Dec 20;19(3):e81 [FREE Full text] [doi: 10.2196/jmir.7097] [Medline: 28320690]

35. Craig P, Dieppe P, Macintyre S, Michie S, Nazareth I, Petticrew M. Developing and evaluating complex interventions: the new Medical Research Council guidance. Int J Nurs Stud 2013 May;50(5):587-592. [doi: 10.1016/j.ijnurstu.2012.09.010] [Medline: 23159157]

36. van der Kop ML, Memetovic J, Patel A, Marra F, Sadatsafavi M, Hajek J, et al. The effect of weekly text-message communication on treatment completion among patients with latent tuberculosis infection: study protocol for a randomised controlled trial (WelTel LTBI). BMJ Open 2014 Apr 09;4(4):e004362-e002013 [FREE Full text] [doi: 10.1136/bmjopen-2013-004362] [Medline: 24719431]

37. Guest G, Bunce A, Johnson L. How many interviews are enough?: An experiment with data saturation and variability. Field Methods 2016 Jul 21;18(1):59-82. [doi: 10.1177/1525822X05279903] 
38. Cai R, Beste D, Chaplin H, Varakliotis S, Suffield L, Josephs F, et al. Developing and evaluating JIapp: acceptability and usability of a smartphone app system to improve self-management in young people with juvenile idiopathic arthritis. JMIR Mhealth Uhealth 2017 Aug 15;5(8):e121 [FREE Full text] [doi: 10.2196/mhealth.7229] [Medline: 28811270]

39. Mummah S, King AC, Gardner CD, Sutton S. Iterative development of Vegethon: a theory-based mobile app intervention to increase vegetable consumption. Int J Behav Nutr Phys Act 2016 Aug 08;13:90 [FREE Full text] [doi:

10.1186/s12966-016-0400-z] [Medline: 27501724]

40. Huang E, Williams H, Hocking JS, Lim MS. Safe sex messages within dating and entertainment smartphone apps: a review. JMIR Mhealth Uhealth 2016 Nov 08;4(4):e124 [FRE Full text] [doi: 10.2196/mhealth.5760] [Medline: 27826133]

41. Fitzpatrick J, Anderson N, Kuppermann M, Steinauer J, Wittman A, Dehlendorf C. Pilot study of "My Birth Control," a contraceptive counseling decision support tool. Contraception 2014 Sep;90(3):320-321. [doi:

10.1016/j.contraception.2014.05.098]

42. Dehlendorf C, Fitzpatrick J, Steinauer J, Swiader L, Grumbach K, Hall C, et al. Development and field testing of a decision support tool to facilitate shared decision making in contraceptive counseling. Patient Educ Couns 2017 Jul;100(7):1374-1381 [FREE Full text] [doi: 10.1016/j.pec.2017.02.009] [Medline: 28237522]

43. Cano J, Foster AM. "They made me go through like weeks of appointments and everything": documenting women's experiences seeking abortion care in Yukon territory, Canada. Contraception 2016 Dec;94(5):489-495. [doi:

10.1016/j.contraception.2016.06.015] [Medline: 27373541]

44. Hulme J, Dunn S, Guilbert E, Soon J, Norman W. Barriers and facilitators to family planning access in Canada. Healthc Policy 2015 Feb;10(3):48-63 [FREE Full text] [Medline: 25947033]

\title{
Abbreviations \\ mHealth: mobile health \\ TAM: technology acceptance model \\ TRA: theory of reasoned action
}

\author{
Edited by G Eysenbach; submitted 21.01.19; peer-reviewed by B Payne, K Reiss, C Smith, D Levine, T Kuhn; comments to author \\ 14.02.19; revised version received 10.04.19; accepted 28.04.19; published 29.05.19 \\ Please cite as: \\ Gill R, Ogilvie G, Norman WV, Fitzsimmons B, Maher C, Renner $R$ \\ Feasibility and Acceptability of a Mobile Technology Intervention to Support Postabortion Care in British Columbia: Phase I \\ J Med Internet Res 2019;21(5):e13387 \\ URL: http://www.jmir.org/2019/5/e13387/ \\ doi: $\underline{10.2196 / 13387}$ \\ PMID: 31144668
}

CRoopan Gill, Gina Ogilvie, Wendy V Norman, Brian Fitzsimmons, Ciana Maher, Regina Renner. Originally published in the Journal of Medical Internet Research (http://www.jmir.org), 29.05.2019. This is an open-access article distributed under the terms of the Creative Commons Attribution License (https://creativecommons.org/licenses/by/4.0/), which permits unrestricted use, distribution, and reproduction in any medium, provided the original work, first published in the Journal of Medical Internet Research, is properly cited. The complete bibliographic information, a link to the original publication on http://www.jmir.org/, as well as this copyright and license information must be included. 